\title{
The Use of Arabic Neologisms in Social Media Applications https://doi.org/10.33806/ijaes2000.21.1.3
}

\author{
Hady J. Hamdan \\ The University of Jordan, Jordan \\ Saleh Al-Salman \\ Applied Science Private University, Jordan
}

\begin{abstract}
This study examines the use of Arabic neologisms in social media applications. It depicts the nature and size of this transformation, and the types of word formation processes which contributed to this phenomenon. The data for this research are collected from two sources: (1) major social media platforms, namely Facebook, Twitter, Instagram, WhatsApp, among others, and (2) the responses of 100 university (under-graduate and postgraduate) students to a limited set of questions in which they are asked to (1) list the most commonly used Information and Communication Technology (ICT) and social mediamotived terms, especially those which have been adapted to and integrated into the Arabic language morpho-phonemic and syntactic system (spoken and/or written), (2) show how often they use those terms especially when an Arabic equivalent/counterpart is available, and (3) give reasons for why they use them. The study shows that use of neologisms is attributed to reasons of practicality and convenience, accuracy and relevance, trendiness and internationalization, in addition to lack of equivalence in the Arabic language system. Further, the following processes which mark the integration of neologisms into the Arabic language system are identified: loan blends, syntactic changes, morpho-syntactic changes, phonemic changes, abbreviations and clipping.
\end{abstract}

Keywords: corpus, lexical semantics, neologisms, social media, word formation process

\section{Introduction}

Customarily, and from a purely linguistic perspective, no language is deemed better than another. In principle, the attributes of a language entail historicity, autonomy, codification, and flexible stability (Wardhaugh 2006). What makes a language what it really means is its rootedness, with a long-standing history and heritage derived and branching from a well-recognized language family tree with its own records of word origins and etymology. In this context, a language should be equipped with the rules that govern and codify all levels of proper linguistic and standardized usage including, phonetics and phonology, morphology, syntax, semantics, and pragmatics (Garvin 1993; Wardhaugh2006). This very feature of codification presupposes a set of rules which empower the language with the most fundamental element of vitality recognizing it as a valid means of communication in different contexts, and for various communicative functions and purposes. Given the interactive nature of languages, they should be flexible enough to allow for interlingual reciprocity, where loanwords and lexical borrowings are sanctioned. 
With this background in mind, dynamic and flexible languages accommodate lexical entries that emerge as a result of technological innovation and scientific advancement. Unless languages show readiness to cope and keep abreast with the new trends in science and technology, they will become rigid and less responsive to the needs of their speakers. Such dynamicity of languages is evidenced in any of the following methods: (1) coining their own lexical and functional equivalents of foreign language terms, or (2) accommodating the new source language (SL) terms in their lexical system as loanwords to be integrated in the target language (TL) system as neologisms, with some minor phonemic, morphological, or syntactic changes to be customized to the TL linguistic norms (Pepper 2020).

The present study investigates the effect of trending social media applications, platforms, and networking websites in influencing discourse. It attempts to (1) furnish a sample list of the most common English terms which have been integrated into the Arabic language system as 'neologisms', (2) probe into the nature of such terms and what marks them as distinct, and (3) identify the morphophonemic changes that these neologisms have undergone once being integrated into the Arabic language lexical inventory.

\section{Review of related literature}

During the last two decades, social media has gained momentum, zest and soul. Lately, the booming market of social media industry through its multimodal manifestations and outreaching arm has made of it a very powerful tool to influence public opinion at the social, economic, political, and ideological levels in critical discourse studies (CDA) (Fairclough 2003; Van Dijk 2011; Wodak 2013). Social media has inarguably become one of the most dominant and powerful sources for the dissemination of news, knowledge, and ideology. Through its multidimensional channels, social media reached out and appealed to all age groups, genders, races, and ethnicities across the globe and in no time.

Al- Salman refers to "the growing power of social media in shaping and influencing all discourse types. Social media can create an alternative source of power which supports the creation of ideologies, cultural attitudes, and political views." The political role of social media in mobilizing public opinion was addressed by Yigit and Tamran (2013: 75) who argue that "social media and networking tools have been one of the most effective tools to direct political elections and social changes." Mallek, Belainine, and Sadat (2017:1) consider Twitter "a very valuable information source for many Natural Language Processing (NLP) applications... and Arabic social media analysis is still an active research area."

With this overwhelming influence of social media on a very wide spectrum of media users regardless of age, class, and ideology, profession, political and ideological affiliation, it is imperative then that language --as a domain of ideology and a major component of social structure-- be influenced as well (Van Dijk 2011)

Crystal (2010:1) posits that "with a language disappearing every two weeks and neologisms springing up almost daily, an understanding of the origins and currency of language has never seemed more relevant." As is clear, Crystal looks 
forward to the future of language and the effect of technology on our day-to-day reading, writing, and speech. In the same vein, Mworia (2015) stresses the importance of Twitter as one of the most prominent social media platforms. She argues:

[A]ge, gender, quickness in communication, meaning impact and avoidance of grammar and spelling conventions were identified as having contributed to the production of social media neologisms. Speed of communication, ease of interpretation and exposure affirm that social media neologisms are effective in communication (p.1).

In contrast, Amedie (2015) highlights the negative role of social media. He maintains that although social media has been useful in many aspects:

[it] has a negative impact on our lives since it is robbing us of trust and comfort we once placed in one another, replacing the human fellowship, physical and emotional support we once drew from each other with virtual connection. It robs us from self-control and from the ability to think independently (p.3).

In an online survey administered in 8 Arab countries (Bahrain, Egypt, Jordan, Kuwait, Lebanon, Oman, Saudi Arabia and the UAE), Mouratada and Salem (2012: 3) concluded that social media in the Arab world has significantly impacted societal and cultural change in the region. A study by Khedher et al. (2015) showed that both standard Arabic, colloquial Arabic, and an English-Arabic mixed orthography (Arabizi) have been used by Arabic social media users. The results indicated that whereas standard Arabic is used in formal discourse, colloquial Arabic and Arabizi are targeted in casual conversation and informal communication. In this regard, Hamdan (2016: 501) reports the use of Arabizi in computer-mediated communication (CMC) among the youth is attributed to ease and swiftness in typing Latin letters since English is the language of the Internet and technology.

Focusing on the translatability of English social media neologisms into Arabic, Kmail (2016) reports that translating and coining Arabic translational equivalents, though attainable, is a very tedious and demanding task. When Arabic equivalents are available, the use of the original English term remains to be the favorite choice and with a much higher rate of fluency and currency.

The authors believe that most social media generated neologisms such as password, selfie, hashtag, save, copy ,paste, snapchat, message, delete, share, like, scan, virus, group, link, junk mail, screenshot, online, offline, attachment, filter, application, underscore, browser, among others, have become fully integrated into the Arabic language colloquial usage, where the overwhelming majority of users would not consider any native Arabic language equivalent. Such words have undoubtedly become the easiest and most favored option to ultimately gain greater currency among almost all social media users, especially the youth. Emery (1983) reports that:

Western technology has been introduced into the Arab world principally through English and French... We have already noted instances of doublets in which the loan word is preferred over its native counterpart. At least here there is a choice, but at the colloquial level it is quite common to find a loan 
technical term for which there is no accepted lexical unit in the Standard Language (p. 87).

Elmgrab (2016) stresses the importance of creating new terminology to cope with the demands of the new age. This task was not quite accessible with classical Arabic, but it has become more so by virtue of the triglossic situation of Arabic where Modern Standard Arabic (MSA) and the colloquial dialects were able to accommodate more foreign terminologies through derivation and blending.

Hameed (2009: 3) identifies the strategies Arab translators use in handling English neologisms into Arabic. He concludes that "contrary to common belief, some of the strategies employed to render English neologisms, like Derivation and Metaphor, are used more often than strategies like Arabicization and Omission". For their part, Awang and Salman (2017: 1) state that "the Arabic Language Academy مجمع اللغة العربية /majmac'Pal-lughati?al-carabiyya/ has always endeavoured to coin native terms in order to domesticate and naturalize foreign terminology into Arabic".

\section{Research Questions}

The present study attempts to find answers to the following questions:

1. Why do Arab users resort to social-media neologisms?

2. What are the most common morpho-syntactic changes and word formation processes affecting these neologisms?

\section{Methodology}

In order to collect the data and identify neologisms, the researchers initially compiled a preliminary list consisting of 145 neologisms retrieved from social media platforms, namely Facebook, Twitter, and Instagram posts, tweets, and blogs, together with a large collection of WhatsApp messages. For neologisms to be included in the list, three criteria had to be met viz., (1) relevance (i.e., either ICT or Social media-oriented terms), (2) frequency (common terms of high frequency), (3) adaptation (neologisms that are integrated into the Arabic language system). Upon compiling the preliminary list and in order to verify the data, the researchers posed a set of questions to a convenient sample of 100 university students (60 under-graduate and 40 post-graduate) coming from different specializations (i.e., Arts/Humanities and Sciences) in which they were requested to:

(1) list the most common/popular and frequently used ICT and social mediamotived terms, especially those which have been adapted to and integrated into the Arabic language morpho-phonemic and syntactic system (spoken and/or written). 
(2) show how often they use those terms especially when an Arabic equivalent/counterpart is available.

(3) give reasons for why they use them.

The total number of items collected from the students was 159. After careful review and comparison between the two lists, i.e., the list collected from major social media platforms and the list collected from students, the researchers identified those items which reflected relevance, high frequency, and adaptability, and accordingly prepared a final list of only 129 items.

\section{Data Analysis}

The data consisted of 129 neologisms which were retrieved from the abovementioned major social media platforms and the 100 students' responses. The data represented authentic conversations retrieved from Facebook, Twitter, and Instagram posts, tweets, and blogs, together with a large collection of WhatsApp messages.

As for the students' responses, they were provided in the form of lists representing the most commonly and frequently used neologisms, and not in a live and interactive conversational exchange. As indicated earlier, the students' responses were mainly utilized for cross-checking and verification purposes, as a control group, to maintain validity and authenticity of the data retrieved from all other social media platforms mentioned above. This is in addition to soliciting answers to the two research questions mentioned above. Qualitatively, the current study is mandated to provide answers to the two questions which guided research in this work.

The cross-checking method of comparing the two sources of data was so fundamental in ensuring reliability and validity of the results. The results have shown that a near-perfect identification of neologisms was detected when analyzing the data. For example, computer and information technology-based terms such as: e-mail, password, username, file, attachment, inbox, junk, among others have been shared by both, especially the academic-research oriented terms which were so frequent in the students' responses. The same applies to most social media terminology where terms such as selfie, hashtag, WhatsApp, among others were detected in the lists of the two data collection sources, as the word lists in the subsequent sections will show.

The set of data collected from the social media platforms focused on neologisms in the field of Information and Communication Technology (ICT) as one package. The data were then divided into two subcategories: (1) computerbased terms, and (2) social media-based terms. Although the boundaries between the two are often fuzzy, the authors were interested in exploring the effect of the relatively new social media applications in adding to the already existing and perhaps more established computer-related neologisms which have been with us for more than three decades. 


\section{Results and discussion}

The data analysis was conducted both quantitatively and qualitatively. Quantitatively, a comprehensive list of neologisms of ICT and social media terms comprising 129 terms was created, (as Tables 1 and 2 below show). The frequency was obtained from Google frequency list, a highly reliable benchmark frequency reference. The list was then divided into two subcategories according to their domain of use, namely computer-based, and social media-based, while acknowledging and stressing the fuzziness of the boundaries between them. In reality, the two categories are interdependent, through a sense relationship of entailment and inclusion. In other words, there is no strict black-and-white distinction between items in the two lists, as they mutually entail each other.

Table 1: Computer-based terms

\begin{tabular}{|l|l|l|l|l|c|}
\hline No. & Word list & Frequency & No. & Word list & Frequency \\
\hline 1 & text & 25270000000 & 38 & videoconference & 1730000000 \\
\hline 2 & E-mail & 18330000000 & 39 & desktop & 1700000000 \\
\hline 3 & sign in & 13710000000 & 40 & Track change & 1650000000 \\
\hline 4 & Link & 12970000000 & 41 & forward & 1590000000 \\
\hline 5 & download & 12940000000 & 42 & Microsoft Word & 136000000 \\
\hline 6 & upload & 10730000000 & 43 & Hard disk & 1300000000 \\
\hline 7 & update & 10020000000 & 44 & Bluetooth & 1240000000 \\
\hline 8 & website & 9970000000 & 45 & Scan & 1080000000 \\
\hline 9 & account & 9340000000 & 46 & delete & 1060000000 \\
\hline 10 & file & 6410000000 & 47 & Attachment & 995000000 \\
\hline 11 & Windows & 5650000000 & 48 & Excel & 837000000 \\
\hline 12 & copy & 5560000000 & 49 & Router & 711000000 \\
\hline 13 & icon & 5450000000 & 50 & paste & 708000000 \\
\hline 14 & Internet & 5260000000 & 51 & Inbox & 676000000 \\
\hline 15 & application & 5080000000 & 52 & Microsoft Teams & 658000000 \\
\hline 16 & Filter & 4900000000 & 53 & User name & 594000000 \\
\hline 17 & Drive & 4740000000 & 54 & spam & 583000000 \\
\hline 18 & CD & 4380000000 & 55 & Google Translator & 552000000 \\
\hline 19 & browser & 4380000000 & 56 & Hackers & 456000000 \\
\hline 20 & dot.com & 4190000000 & 57 & junk mail & 439000000 \\
\hline 21 & settings & 4140000000 & 58 & Modem & 372000000 \\
\hline 22 & PDF & 4000000000 & 59 & PowerPoint & 349000000 \\
\hline 23 & Block & 3740000000 & 60 & restart & 135000000 \\
\hline 24 & favorites & 3690000000 & 61 & Reverso Translate & 133000000 \\
\hline 25 & WhatsApp & 3630000000 & 62 & formatting & 119000000 \\
\hline & & & & & \\
\hline
\end{tabular}




\begin{tabular}{|l|l|l|l|l|l|}
26 & keyboard & 3370000000 & 63 & antivirus & 112000000 \\
\hline 27 & password & 3290000000 & 64 & Turnitin & 97200000 \\
\hline 28 & connection & 3270000000 & 65 & Bing Translator & 51900000 \\
\hline 29 & cancel & 3260000000 & 66 & YOLO & 47000000 \\
\hline 30 & install & 2790000000 & 67 & underscore & 32700000 \\
\hline 31 & Admin & 2660000000 & 68 & voicemail & 28300000 \\
\hline 32 & DVD & 2570000000 & 69 & Megabyte & 15100000 \\
\hline 33 & Edit & 2570000000 & 70 & clickbait & 10500000 \\
\hline 34 & USB & 2290000000 & 71 & Listicle & 4540000 \\
\hline 35 & laptop & 2020000000 & 72 & Hashtag & 3790000 \\
\hline 36 & virus & 1980000000 & 73 & Unfriend & 3350000 \\
\hline 37 & Server & 1770000000 & 74 & $@$ & 2900000 \\
\cline { 4 - 6 } & & & 75 & Systran translate & 465000 \\
\hline
\end{tabular}

Table 1 shows that all 75 entries which comprise the most predominant computer-oriented terms have been googled to show their level of frequency registered in the world's leading search engine. It is worth noting that the figures which are often estimated at billions, do not necessarily reflect the one term's independent use, but they refer to the number of pages reflecting the concordances of this item in combined words and terms. The authors' resorting to Google's frequency list as a quantification method was driven by the importance of having a highly reliable benchmark of frequency reference.

Table 1 comprises a good collection of ICT proper terminology which is primarily computer-based, but it still falls at the heart of the social media glossary. For example, computer and information technology-based terms such as: e-mail, sign in, password, username, file, attachment, inbox, junk, refresh, click, delete, scan, send, save, download, desktop, laptop, printer, server, browser, website, , spam, forward (an email), virus, USB, Bluetooth, PowerPoint, track changes, keyboard, font, hackers, etc. score a remarkably high level of frequency among the average Arab ICT users. In other words, it is the original English term and not its Arabic equivalent, if any, that was the right option for the sample members. For higher studies students, MA and Ph.D. level, the English original terms give them better access to search engines for their academic research projects. This is due to the inability of the Arabic equivalents such as نسخ /naskh/, لصق /lasq/ to compete with and replace the English copy and paste, or terms like الثبكة العنكبوتية/RashshabakaPal'ankabu:tiyya/ to replace Internet, and even words such

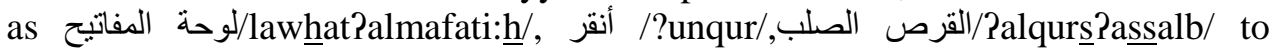
replace and cope with the highly frequent English words keyboard, click, hard disk, among others. 
Table 2: Social Media-based terms

\begin{tabular}{|l|l|l|l|l|l|}
\hline No. & Word List & Frequency & No. & Word List & Frequency \\
\hline 1 & Facebook & 25270000000 & 28 & chat & 3050000000 \\
\hline 2 & Video & 25270000000 & 29 & multimedia & 2360000000 \\
\hline 3 & image & 25270000000 & 30 & Mention & 1780000000 \\
\hline 5 & home page & 22620000000 & 31 & Messenger & 1590000000 \\
\hline 6 & Like & 14830000000 & 32 & Followers & 1540000000 \\
\hline 7 & Ads & 14410000000 & 33 & SMS & 1490000000 \\
\hline 8 & online & 13630000000 & 34 & Selfie & 1430000000 \\
\hline 9 & share & 13470000000 & 35 & homepage & 1290000000 \\
\hline 10 & contact & 12180000000 & 36 & Tik Tok, & 1190000000 \\
\hline 11 & Twitter & 11630000000 & 37 & GPS & 1190000000 \\
\hline 12 & comment & 10730000000 & 38 & podcast & 1190000000 \\
\hline 13 & Group & 10510000000 & 39 & Lol & 1100000000 \\
\hline 14 & blog & 10170000000 & 40 & iPad & 1060000000 \\
\hline 15 & Google & 10040000000 & 41 & Streaming & 989000000 \\
\hline 16 & Instagram & 9870000000 & 42 & Snap & 820000000 \\
\hline 17 & YouTube & 9730000000 & 43 & offline & 669000000 \\
\hline 18 & Profile & 8890000000 & 44 & Skype & 568000000 \\
\hline 19 & Google Play & 8590000000 & 45 & refresh & 553000000 \\
\hline 20 & e-book & 7650000000 & 46 & Viber & 539000000 \\
\hline 20 & tag & 7250000000 & 47 & photoshop & 519000000 \\
\hline 21 & join & 6410000000 & 48 & Emoji & 411000000 \\
\hline 22 & screen shot & 6250000000 & 49 & cropping & 338000000 \\
\hline 23 & fans & 4860000000 & 50 & Snapchat & 327000000 \\
\hline 24 & subscribe & 4220000000 & 51 & Imo & 179000000 \\
\hline 25 & screenshot & 3940000000 & 52 & trimming & 96400000 \\
\hline 26 & Status story & $3,910,000,000$ & 53 & True caller & 94800000 \\
\hline 27 & Trend & 3230000000 & 54 & Woot & 71600000 \\
\hline & & & & \\
\hline
\end{tabular}

As indicated earlier, Tables 1 and 2 are thematically similar as they represent ITC terminology. In other words, the two lists are interdependent. In reality, there are no strict black-and-white distinctions between items of the two list, where any of them may part of the other. Perhaps such a formal and not content-based division is only meant to shed light on the newly added social media-oriented English terms which have been integrated into the Arabic language system as neologisms in the last 10 years following the trending wave of social media craze. 
Parallel to the treatment of Table 1 above, Table 2 was similarly subjected to Google search quantification of frequency as a benchmark of data authenticity. This is with the understanding that the figures, which often show11-digit number frequencies, do not reflect the single term's actual frequency of use, but only give a rather rough estimate of the concordances where the term has occurred.

To this end, and to further dismiss any doubts on the question of frequency, and to explore the degree of integration of these neologisms in the Arabic language morpho-phonemic, syntactic, and semantic systems, the data were subjected to further testing. The lists were fed into Sketch Engine, a corpus manager and text analysis software which yields reliable information on the distributional analysis of Key Words in Context (KWIC); collocation/co-occurrence analytical search for words which are considered collocates; concordance search for word forms/phrases and complex structure. The degree of integration and adaptation of neologisms rests upon identifying and plotting the most prominent morpho-phonemic, syntactic changes and word-formation processes affecting neologisms, including derivation, affixation, coinages, loan renditions, blending, compounding, clipping, acronyms, etc.

As is the case in Table 1 findings, Table 2 reflects a high frequency of terms which are methodologically linked to social media applications, a trend which has been vastly expanding and accelerating in the last decade. A close investigation of the data shows that those terms have not only been popular among the average social media user, but also were the dominant expressions in social interaction across social media platforms such as: Facebook, Twitter, Instagram, WhatsApp, etc. The student sample identified a wide range of social media-based terms which constituted the bulk of their everyday ICT terminology. For example, terms like Internet, selfie, hashtag, settings, location, Google search, group, WhatsApp, share, like, snapchat, blogger, photoshop, offline, apps, subscribe, join, profile, filter, screenshot, Emoji, True caller, voicemail, among others, were the favored terms in their daily ICT and social media-based interactions. Again, for them, the Arabic counterpart, if available, was not their first choice. The English version is the one being recognized in search engines, let alone the every-day online communication. Lately, and in the wake of the devastating COVID-19 pandemic, the e-learning platforms have become the only viable solution to providing educational services at all levels. This emerging situation has maximized the importance and the fundamental role of social media platforms in disseminating news and knowledge and reaching out to everybody in times of crisis.

With regards to the research questions posed earlier in the study, the results, obtained from the two lists in Tables 1 and 2, have inarguably shown that neologisms enjoy a very high level of frequency. This has been confirmed through the data obtained in the tables which were characterized with comprehensiveness, diversity, and high frequency, as evidenced in the examples given above.

To verify the frequency of the 129 items identified in the above lists, the authors googled a number of Arabic language knowledge resources in different genres and disciplines. These included technical, scientific, economic, medical, linguistic, media, entertainment and sports-related texts. The results showed that 
many of these words have high frequency of occurrence in spoken/colloquial usage but do exist in formal usage as well, in varying degrees. For example, words like mobile/ مبيوتر mo:bayl/, Internet موبايل

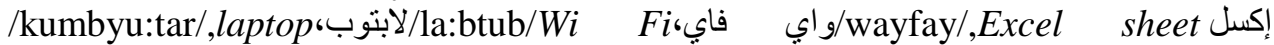

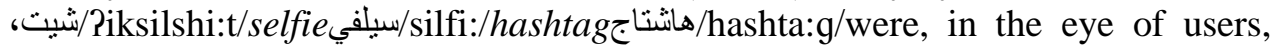
considered trending neologisms. Furthermore, words like جروب/gru:b/شيرو/She:r/, الايك /layk/bluk/ for the English original "block, like, share, and group" respectively, have become an integral part of social media users' daily practice.

In the view of the participants' responses, neologisms are used for the following reasons:

1. Practicality and convenience: The responses stressed the importance of using terms which are recognized globally and are compatible with modern-day technical and technological advancements, driven by innovations in science and technology. As many of the respondents put it, "English has the upper hand, well above other languages".

2. Accuracy and relevance: All 100 respondents were of the opinion that the English language terms and expressions are gaining higher currency due to their close relatedness to the register and specialized terminology in their fields of study. The glossary of the ICT terminology whether computerbased or social media-based helps users cope with hi-tech and state-of-theart digital technology and gadgets. This enables them to reach out to the outer world and be closer to world political, scientific, medical, social events, in addition to entertainment, among others. As they put it, "Arabic terms and equivalents, if any, are scanty and often lacking in accuracy and adequacy".

3. Trendiness: About 90 per cent of the students' responses favored the use of English words in their everyday communication and social interactions through e-mails, messages, chats, tweets, posts, blogs, forums, etc. due to their evolving nature as trendy terms that reflect modernity, social status, and perhaps prestige. To their mind, English represents the stereotype of a modern and stylish language for fashion, sports and entertainment. This was the trend among younger age student groups, especially those enrolled in the undergraduate programs. The trendiness variable was not as evident in the responses of postgraduate students whose responses were more motivated by academic considerations.

4. Internationalization: A high percentage of the responses (95\%) linked the use of neologisms with openness to and rapprochement with the outside world. For them, globalization and internationalization are closely associated with Internet digital applications and technology. Nowadays, all international transactions require a high-level of digital literacy to help one cope with technological innovations in all walks of life. Online services have become the vogue of the age which is fueled by digital technology and its applications. This has been the trend in trade, industry, travel, tourism, merchandise, businesses, knowledge, information, social 
interaction, etc. All the above-mentioned domains require an advanced level of knowledge in surfing the Internet for searching and sharing information through electronic devices, smart phones for web browsing, networking, e-mail services, and social media applications. In the view of many participants, "English is the world's lingua franca".

5. Insufficient Arabic language word stock: About $90 \%$ of the responses expressed concern about the dearth in the Arabic language lexical inventory in the ICT field to cope with the growing demand on Internet-based social media terminology. As the examples above have shown, many Arabic coined terms in everyday applications of digital technology failed to compete with their parallel English originals, which continued to dominate the scene. For example, in-depth original research requires high level of Internet and computer literacy and know-how to meet top-level academic research requirements, a condition which most Arabic derived terms do not fulfil.

With regard to the second research question, namely the most common morpho-syntactic changes and word formation processes affecting neologisms in Arabic, the results have shown that neologisms have been directly influenced by morphological changes including derivation and affixation. The same applies to grammatical changes related to word-class membership, grammatical class (i.e., parts of speech). Foreign words borrowed into Arabic tend to adjust to its morphophonemic systems (Khrisat and Mohamad 2014).Given that Arabic is a triglossic language where three varieties of the language are used, classical, Modern Standard Arabic (MSA), and colloquial Arabic, the adaptation of neologisms was more accessible in the non-standard varieties of Arabic where the morpho-phonemic, and syntactic systems were more flexible. The standard variety of Arabic was less tolerant to the total integration of neologisms, while allowing for the use of some lexical items like radio, television, Internet, computer, video, mobile, etc. Similarly, social media platforms like Facebook, Twitter, Instagram, YouTube, WhatsApp, etc. were integrated into standard Arabic as loanwords.

Upon discussing the relationship between neologisms and word-formation processes, two aspects need to be addressed (1) characterizing the linguistic processes which affect neologisms, as to how they occur, and (2) explaining why they occur.

With regard to the characterization of the linguistic processes, it is important to examine the most dominant morpho-phonemic, syntactic, and word-formation processes which mark the integration of neologisms into the Arabic language system. These processes and their linguistic characterization may be summed up as follows:

1. Loan blends: This is a process which entails the selection of a loanword used as a stem to which a native inflectional morpheme is annexed (e.g., (mobile) /mo:bayl/ $\rightarrow$ /mo:bayli:/ $\rightarrow$ /mo:bayla:t/. In the examples provided above, the two affixes that are added to the loanword used as a stem are: (1) the genitive case marker Arabic 
suffix -i 'my' (first person) /i:/ as in the case of موبايلي 'my mobile' /mo:bayli:/ and (2) the plural forming Arabic suffix -at /a:t/ as in the case of موبايلات 'mobiles'/mo:bayla:t/.

2. Syntactic changes, which may be demonstrated in the following cases:

- Where English verb forms have, as neologisms, been integrated and naturalized into the Arabic grammatical system, representing a case of Arabicization (i.e., English words are written in Arabic orthography), e.g., cancel $\rightarrow$ (كنسل) /kansil/; delete $\rightarrow$ دَلّّت /dallit/; save $\rightarrow$ سيٌّ /sayyiv/.This structure/formation represents an advanced state of syntactic integration in the Arabic verb system.

-Change of grammatical category/ word-class membership. This occurs when some neologisms which have been fully integrated into the Arabic language system change their grammatical category/part of speech. For example, the word 'message' (n.) has been used as verb 'to send a message' $\rightarrow$ يمسيّف $\rightarrow$ /Pisayyiv/; to format (a computer) $\rightarrow$ يفرمت /Pifarmit/ and to file يفيّل /Pifayyil/.

3. Morpho-syntactic changes, the 'passive participle' اسم المفعول/Pism Pal maf $^{\mathrm{c}} \mathrm{u}: 1 /$ : In some cases, neologisms, through a process of derivation, have changed their grammatical form. For example, the verbs 'save, share, and format' have taken the 'passive participle' form as in: "saved

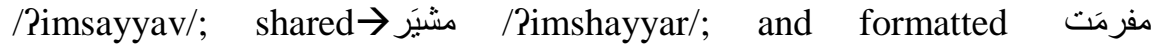
/Pimfarmat/", respectively.

4. Phonemic changes: This occurs when a change takes place in the pronunciation of some English words after being integrated into the Arabic language system due to native language interference. For example, since the Arabic sound system does not have in its phonemic inventory a voiced labiodental fricative /v/, and a voiceless bilabial plosive /p/, neologisms with a /v/ and /p/ are pronounced with their Arabic counterparts /f/ and b/, respectively. In this case words like 'laptop' and 'Power Point' would be pronounced as بوَربوينت/ لاب /labtub/ and bawboint/, respectively. The notion of native language interference was addressed by Farrah and Halahlah (2020: 204) who reported that "because there is a clear mismatch in the Arabic and English sound systems, English students at Hebron University face a number of difficulties in English pronunciation. One difficulty is found in some sounds that do not exist in the Arabic sound system such as the consonants /p/, /t $\int, / 3 /, / \mathrm{v} / . "$

5. Abbreviations: Many neologisms have been integrated into Arabic as abbreviations. This applies to terms such as واي فاي /way fay/WI FI (آتش تي تي بي,/Rayti:/ IT (Information Technology)

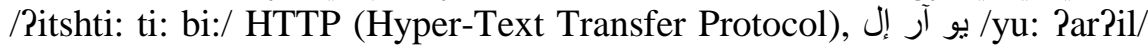

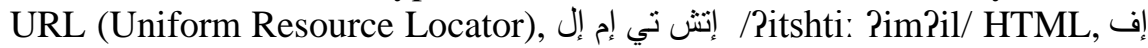
بي آبي بي,/Pay bi:/ IP (Internet Protocol), بي دي إف/bi: di: Pif/ PDF (Portable Document Format).

6. Clipped forms: for example, the word 'applications' has been used in its clipped form آبس/Ra:bs/ 'apps'; the word 'Snapchat' has been used in its 
clipped form سناب/sna:b/ 'snap'; the word 'Facebook' has been used in its clipped form فيس /fe:s/ 'face'.

The previous examples show that many neologisms have acquired higher frequency than their Arabic counterparts such as "نليفون/tilifo:n/ vs. هاتف/ha:tif/,

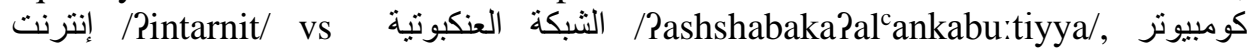
/kumbyu:tar/vs.حسوب/ha:su:b/ردايو/ra:dyu/vs مذياع/midhya/to the extent that they have been adapted to the morpho-syntactic processes of derivation and affixation

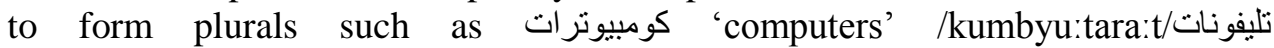
'telephones'/tilifo:na:t/. In other cases, the neologisms have been fully integrated into and adapted to the Arabic language grammatical system to take fully-fledged verb forms as in the very common ITC terms: (to save $\rightarrow$ / Risayyiv/ (يسَيف; to share $\rightarrow /$ Rishayyir/ (يشيرَ); and to format $\rightarrow /$ iffarmit/(يفرمت). It is often the case that borrowed words undergo linguistic changes to fit the phonological, morphological, and syntactic patterns of the recipient/borrowing language.

As to why these linguistic processes occur, it is very important to establish a correlation between the linguistic characterization of neologisms and the chances of their survival and persistence. The types of neologisms which acquire the status of adaptation to the Arabic language morpho-phonemic and syntactic system will most likely persist and become an integral part of the lexical repertoire of Arabic. This applies mainly to neologisms which are driven by scientific discoveries and technical innovations. The global circulation and dissemination of those specialized innovations is accelerated through using the indigenous term coined for a particular product or concept. Typically, trending words and terms travel fast globally in the original/indigenous language of their creation. More often than not, those coinages end up being the first choice by users in borrowing countries even after native language equivalents are provided. This is due to their popularity, ease, and effectiveness in communication. For example, digital technology terms and their applications such as Zoom, Teams, MOOCs (Massive Open Online Courses) have been fully integrated into the Arabic language system. The high frequency of using those neologisms by Arabic language users indicates that they will persist and survive, even after some Arabic language equivalents have been coined by the Arabic language academies, as the above-mentioned examples of share, save, and format, among others, show. It is noteworthy, however, that in some cases the creation of a native language equivalents may gain currency and acceptance among some groups, where it will replace the loan term or co-exist with it. Evidence of this

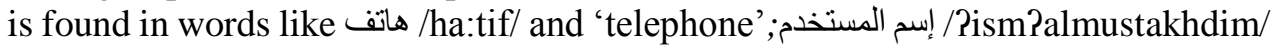
and 'user name'; الرقم السري/Parraqampassirri/and 'password'.

As part of the dynamics of lexical innovations, it is noteworthy that neologisms come and go; new words are coined all the time. This suggests that the fate of lexical innovations is unpredictable. For example, some terms which used to be so popular at some point in time, may disappear if the concept/object they refer is no longer in use, even if the term had been fully-integrated into the recipient language's morpho-syntactic system. As a rule, lexical innovations are the product of both language and cultural contact. For example, the word 'cassette-recorder' 
has become obsolete and consequently was replaced by the term 'video-player'. Also, the word 'floppy disk' has been replaced by 'USB flash drive'.

Interestingly, our fathers and grandfathers have witnessed and experienced some neologisms of foreign origin which have been fully integrated into the Arabic language system during the 1940's, 50's, and 60's of the last century, and which -at that time-- were dominant without any competitive native language counterpart. For example, the words طبيل/tumbi:1/ 'automobile'; فرمشية/farmashiyye/ 'pharmacy'; إسبيطار /isbitar/ 'hospital', were so dominant and popular that the Arabic language equivalents صيدلية ،سيارة ، مستشفى were hardly used at that time. But, at a later stage, the situation has completely changed with the new generation of users, 1970's and after, when the native Arabic language words صيدلية ،سيارة, and طمبيل have completely replaced those neologisms of foreign origin, namely مستشفى respectively.

Another important factor that would determine the survival of lexical innovations is the 'distribution rate criteria', which shows how often a neologism appears in publications. In other words, more frequent the appearance in publications is indicative of higher chances for persistence and survival.

\section{Conclusion}

There is no truer evidence to the popularity, power and effectiveness of social media platforms than the methodological use of social media platforms by world leaders and politicians for interaction, communication or propaganda. Their tweets often carry major decisions and breaking news, a practice which has never been exercised before. With this magnitude, zest and influence of social media, languages have been impacted heavily by the voluminous flux of social media terminology. For languages to cope with the remarkably increasing rate of innovations in science and technology, neologisms have inevitably been a new source for lexical semantics to address.

The current piece of research has most succinctly shown that Arabic has been heavily influenced by the thrust of social media platforms. The two research questions addressing the frequency and spread of social media-motivated neologisms, reasons and rationale, their integration and adaption to the Arabic language patters, and the potential effects of neologisms on the Arabic language have confirmed the importance and undisputed role of social media-generated terms in facilitating communication and interaction in different disciplines. The study has shown that even in those cases where the Arabic language equivalents have been rendered through word formation process of coinages, derivation, hybridization, loan translations, etc., the authentic English language form remains the most dominant. For example, neologisms in the form of internationalisms such as Google Play, Appstore, Twitter, Facebook, Google, etc., have been fully integrated into Arabic. The same applies to abbreviations such as IT (Information Technology), HTTP (Hyper-Text Transfer Protocol, URL (Uniform Resource Locator), (HTML (Hypertext Markup Language), FTP (File Transfer Protocol/ File Transfer Program), IP (Internet Protocol), etc. Even in the case of neologisms which have Arabic language counterparts such as: user name 'اسم المستخدم'/PismPalmustakhdim/; 


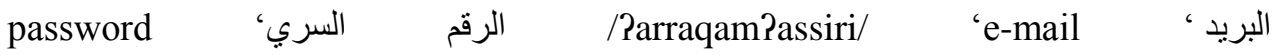
'الاكتروني English version was remarkably higher as they were largely naturalized in the TL system.

To conclude, language contact is a universal phenomenon which is there to stay. Loanwords and neologisms as an offshoot of this state, are a characteristic feature of living languages which are in constant state of evolution and change. Individual languages are therefore required to adapt to this phenomenon by fortifying their language systems against decay and death. As for the Arabic language, the negative effect of social media neologisms is only minimal and does not call for concern. On the contrary, Arabic has long been known to be a donor language, and Arabic language academies and language planning experts have played a major role coping with the emerging technical terminology and stepping up the Arabic language lexicographic and encyclopedic stock. But after all, the study has most evidently highlighted the effectiveness of social media neologisms in communication at all levels.

Hady J. Hamdan

Department of English Language and Literature

The University of Jordan, Jordan

ORCID Number: 0000-0003-0146-511X

Email: hady_hamdan@windowslive.com

Saleh Al-Salman

Department of English Language and Literature

Applied Science Private University, Jordan

ORCID Number: 0000-0002-0103-1330

Email: salehalsalman2000@gmail.com

\section{References}

Al-Salman, Saleh. (2017). 'Has the power of language been compromised by the influence?'. Studies in English Language Teaching, 5 (2):172-185.

Amedie, Jacob. (2015). The impact of social media on society. http://scholarcommons.scu.edu/engl 176. (Retrieved on 25 January, 2020.

Awang, Rokiah and Ghada Salman. (2017). 'Translation and Arabicization methods of English scientific and technical terms into Arabic'. AWEJ for Translation \& Literary Studies, 1 (2):92-106.

Crystal, David. (2010). A Little Book of Language. Yale University Press.

Elmgrab, Ramadan. (2016). The Creation of terminology in Arabic'. American International Journal of Contemporary Research, 6 (2): 75-85.

Emery, Peter. (1983). Towards the creation of a unified scientific terminology in Arabic.

https://pdfs.semanticscholar.org/0fb5/8e109c2c098da4d3d913b6a519fd459 4a510.pdf (Retrieved on 8 September, 2020). 
Fairclough, Norman. (2003). 'Political correctness: The politics of culture and language'. Discourse and Society, 14 (1): 17-28.

Farrah, Mohammed and NadiaHalahlah. (2020). 'Pronunciation problems among Palestinian English major students in Hebron University'. International Journal of Arabic-English Studies (IJAES), 20 (1): 203-226.

Garvin, Paul. (1993). 'A conceptual framework for the study of language standardization'. International Journal of the Sociology of Language, (100/101): 37-54.

Hamdan, Hady. (2016). 'Attitudes towards Arabic romanization and student's major: Evidence from the University of Jordan'. Arab World English Journal (AWEJ), 7 (4): 493-502.

Hameed, Sinan. (2009). Coping with neologisms in English/Arabic translation. Published MA Thesis, American University of Sharjah, Sharjah, United Arab Emirates.

Khedher, Zeki, GheithAbandah, Waleed Al-Anati, Sami Ababneh, Ahmad Zghoul, and MamounHattab. (2015). Effect of topic on the Arabic language used on social networks and mobile phone communications. https://ieeexplore.ieee.org/document/7360593 (Retrieved on 8 September, 2020).

Khrisat, Abdulhafeth. and Majiduddin Mohamad. (2014). 'Language's borrowings: The role of the borrowed and Arabized words in enriching Arabic language'. American Journal of Humanities and Social Sciences, 2 (2): 133 - 142 .

Kmail, Rahma. (2016). The Translatability of English Social Media Neologisms into Arabic. Unpublished MA thesis, Al-Najah University, Palestine.

Mallek, Fatma; BillaBelainine; and Fatiha Sadat. (2017). 'Arabic Social Media Analysis andTranslation'. Procedia Computer Science, 117: 298-303.

Mourtada, Racha, and Fadi Salem. (2012). 'Social Media in the Arab World: Influencing Societal and Cultural Change?' Arab Social Media Report series, 2 (1): 1-29.

Mworia, Ruth. (2015). Use of English neologisms in social media: A case of Twitter language in Kenya. Unpublished MA thesis, University of Nairobi, Kenya.

Pepper, Steve. (2020). The typology and semantics of binominal lexemes: Nounnoun compounds and their functional equivalents. Unpublished $\mathrm{PhD}$ Dissertation, University of Oslo, Norway.

Van Dijk, Teun (ed.) (2011). Discourse Studies: A Multidisciplinary Introduction. London: Sage Publications, Ltd.

Wardhaugh, Ronald. (2006). An Introduction to Sociolinguistics. New York: Basil Blackwell.

Wodak, Ruth (ed.) (2013). Critical Discourse Analysis: Concepts, History, Theory. London: Sage Publishing Ltd.

Yigit, Mehmet, and Bulent Tarman. (2013). 'The Impact of Social Media on Globalization.' Journal of Social Science Education, 12 (1): 75-80. 